REGARDS

SUR L'ECONOMIE ALLEMAND

BULLETIN ECONOMIQUE DU CIRAC
Regards sur l'économie allemande

Bulletin économique du CIRAC

$79 \mid 2006$

Varia

\title{
Commerces : horaires libres, sauf en Bavière
}

\author{
Isabelle Bourgeois
}

\section{OpenEdition}

Journals

Édition électronique

URL : http://journals.openedition.org/rea/734

DOI : 10.4000/rea.734

ISBN : 978-2-8218-0854-6

ISSN : 1965-0787

Éditeur

CIRAC

Édition imprimée

Date de publication : 1 décembre 2006

Pagination : $37-38$

ISSN : 1156-8992

Référence électronique

Isabelle Bourgeois, "Commerces : horaires libres, sauf en Bavière », Regards sur l'économie allemande [En ligne], 79 | décembre 2006, document 1, mis en ligne le 01 décembre 2008, consulté le 15 septembre 2020. URL : http://journals.openedition.org/rea/734

Ce document a été généré automatiquement le 15 septembre 2020.

(C) CIRAC 


\title{
Commerces : horaires libres, sauf en Bavière
}

\author{
Isabelle Bourgeois
}

1 C'est l'une des retombées de la réforme du fédéralisme, entrée en vigueur le $1^{\text {er }}$ septembre, et qui avait allongé la liste des compétences législatives des Länder : ce sont eux qui décident désormais des horaires d'ouverture des magasins. Ils se sont empressés d'user de leur nouveau pouvoir pour mettre fin à un "acquis social» historique, né il y a exactement 50 ans dans le contexte du miracle économique : la Loi (jusqu'ici fédérale) sur la fermeture des magasins - ce Ladenschlussgesetz du 28-11-1956.

\section{La libéralisation concerne surtout les jours ouvrables}

2 Désormais, les horaires sont/seront libres (ou presque) dans la plupart des Länder. Mais, chaque Land légiférant de manière autonome, la réglementation est très disparate. Quelques exemples: Berlin a ouvert le bal; depuis le 17 novembre, les commerces sont ouverts 24 heures sur $24 \mathrm{du}$ lundi au samedi. S'y ajoutent 10 dimanches dans l'année, la disposition la plus libérale de toute l'Allemagne. La Rhénanie du Nord-Westphalie a suivi le 21 novembre, limitant toutefois l'activité dominicale à 4 dimanches ou jours fériés dans l'année ; ce sont les communes qui fixent les dates. Parallèlement, les régimes spécifiques (stations-service, aéroports, stations thermales...) applicables à ces jours chômés, et qui existaient avant la libéralisation, sont maintenus. La Thuringe et la Saxe (30 novembre) ont adopté des dispositions similaires pour les dimanches et jours fériés, mais plus restrictives pour les jours ouvrables (fermeture à 20 heures le samedi).

\section{En Bavière, le conservatisme l'emporte}

Dans les autres Länder, l'entrée en vigueur des nouvelles lois, plus ou moins libérales, s'échelonne entre décembre 2006 et le printemps 2007. Seule, la Bavière n'a rien entrepris, préférant attendre l'évolution dans les autres Länder. "C'est une décision de 
bon sens", se réjouit le syndicat des services ver.di qui est depuis toujours farouchement opposé à toute libéralisation pour accroître son influence dans un secteur dont la régulation lui échappe largement, notamment du fait d'un degré d'organisation particulièrement faible. Ver.di n'hésite pas, cette fois non plus, à se féliciter de la coalition d'intérêts qui le lie aux Eglises protestante et catholique au sujet de la défense du jour du Seigneur. Elle avait abouti au rejet, par la Commission CSU (largement majoritaire) du Landtag de Bavière, de la loi de libéralisation présentée par le ministre de l'Economie bavarois. Dans l'Etat libre, le conservatisme des corps intermédiaires reste puissant...

\section{Une protection des salariés qui souffrait trop d'exceptions}

4 Malgré de nombreuses tentatives de réforme, et malgré des assouplissements intervenus en 1989, en 1996, puis en 2003 (voir REA 60/03), syndicats et Eglises avaient toujours fait obstruction à une libéralisation de l'ouverture des commerces. Pourtant, les consommateurs, eux, rêvent depuis longtemps d'une adaptation des horaires à leurs modes de vie et de loisirs qui ont considérablement évolué en 50 ans. Quant aux salariés, leurs droits n'étaient plus guère protégés par un Ladenschlussgesetz multipliant, au fil de ses révisions, les régimes d'exception. En 2004, le Tribunal constitutionnel fédéral avait certes déclaré cette loi conforme à la Constitution (à une courte majorité toutefois) et protégé le repos dominical, mais estimé dans le même temps que, les horaires des magasins déterminant la vie des salariés comme des consommateurs dans leur cadre de vie, leur réglementation devrait revenir aux Länder (voir REA 67/04). Le transfert des compétences nécessaire a été opéré avec la réforme du fédéralisme.

\section{Difficiles négociations en vue avec ver.di}

Les conséquences sur l'économie sont difficiles à estimer. Pour les commerçants, la libéralisation pourrait s'accompagner d'une hausse de la masse salariale (heures supplémentaires...), étant donné que la convention collective en vigueur dans le commerce de détail n'a, elle, pas été modifiée. Mais les négociations avec ver.di s'ouvrent au printemps. D'ores et déjà, le syndicat des employeurs a dénoncé les accords-cadres; les négociations sur les nouvelles grilles de rémunération s'annoncent rudes.

\section{Un impact sur la consommation impossible à évaluer}

La fédération du commerce de détail (HDE), pour sa part, s'inquiète de ce "patchwork " réglementaire qui n'accroît guère la transparence. Et elle reste prudente quant à l'évolution de la consommation. Un pic à l'approche de Noël est normal, surtout les samedis de la période de l'Avent, aux horaires traditionnellement élargis. La hausse de la TVA ne devrait guère inciter les Allemands à acheter plus en 2007, même à des horaires plus favorables pour les salariés, notamment les femmes. Leur pouvoir d'achat reste limité ; selon Destatis, leur revenu réel moyen a baissé de $2 \%$ depuis 1991. 


\section{Restructuration à venir dans le commerce}

7 En revanche, la libéralisation pourrait avoir un impact sur la VPC qui offrait aux Allemands une échappatoire à des horaires trop restrictifs, de même que sur le commerce en ligne, actuellement en plein essor. Les Allemands ont effectué des achats sur Internet d'une valeur de plus de 10 milliards $€$ en 2006 selon la fédération de la VPC. C'est peu face au chiffre d'affaires du commerce de détail (390 milliards $€$ ), mais la progression est de $35 \%$ par rapport à 2005. Quant à la fédération du commerce en ligne, elle estime le chiffre d'affaires de 2006 à plus de 16 milliards $€$, soit une progression de $12 \%$. La libéralisation des horaires des magasins pourrait affecter la structuration même du commerce allemand en menant à une nouvelle répartition des activités et parts de marché entre grands magasins et commerce de proximité spécialisé, entre commerce traditionnel et commerce par correspondance. A en croire la fédération HDE, les Allemands vont repérer les produits sur Internet, mais vont les acheter dans les magasins...

Quoi qu'il en soit, la réforme répond à la demande des consommateurs en abrogeant une réglementation frappée d'obsolescence par les mutations de l'économie et de la société. Et elle est susceptible d'impulser une nouvelle culture des services.

\section{INDEX}

Mots-clés : Bavière, commerce, consommation, distribution, horaire, libéralisation 